\title{
Tanalith-E ile emprenye işleminin masif ağaç malzemenin yüzey pürüzlülüğüne etkileri
}

\author{
Hakan Keskin $^{1 *}$ (D), Ramazan Bülbül ${ }^{1}$
}

$\ddot{\mathbf{O} z}$

$\mathrm{Bu}$ çalışma, Tanalith-E ile emprenye etmenin odunun yüzey pürüzlülüğüne etkilerinin belirlenmesi amacıyla yapılmıştır. Bu maksatla, Türkiye'de yaygın olarak kullanılan Doğu kayını (Fagus orientalis Lipsky), Sarıçam (Pinus sylvestris Lipsky), Sapsız meşe (Quercus petraea Liebl.) ve Uludağ göknarı (Abies nordmanniana subsp. Bornmüllerana Mattf.) odunları Tanalith-E emprenye maddesi ile ASTM D 1413 standardı esaslarına göre kısa süreli (10 dakika) orta süreli (2 saat) daldırma metodu ile emprenye edilmiştir. Emprenye edilen deney örneklerinin yüzey pürüzlülüğ̈ TS EN 971 standartları esaslarına göre belirlenmiştir. Deney sonuçlarına göre; ağaç türlerine göre en yüksek ortalama Ra yüzey pürüzlülügü değerleri; kısa süreli emprenye edilen sapsız meşede $(5.22 \mu \mathrm{m})$, sırası ile kayında $(4.80 \mu \mathrm{m})$, göknarda $(3.42 \mu \mathrm{m})$ ve sarıçamda $(3.03 \mu \mathrm{m})$ elde edilmiştir. Orta süreli emprenye edilen sapsız meşede $(6.42 \mu \mathrm{m})$, kayında $(5.020 \mu \mathrm{m})$, göknarda $(4.24 \mu \mathrm{m})$ ve sarıçamda $(3.74 \mu \mathrm{m})$ elde edilmiştir. Sonuç olarak, Tanalith-E ile kısa ve orta süreli emprenye işlemi yüzey pürüzlülügü değerlerini arttırmıştır. Yüzey pürüzlülügü değerinin az olması istenilen yerlerde sarıçam odunu kullanımı önerilebilir.

Anahtar Kelimeler: Yüzey pürüzlülüğü, emprenye, Tanalith-E, ağaç malzeme

\section{Impacts of impregnation with Tanalith-E on surface roughness of solid wood materials}

\begin{abstract}
This study was carried out to determine the impacts of impregnation with Tanalith-E on surface roughness of solid wood materials. For this purpose, Oriental beech (Fagus orientalis Lipsky), Scotchpine (Pinus sylvestris Lipsky), European oak (Quercus petraea Liebl.) and Uludag fir (Abies nordmanniana subsp. Bornmüllerana Mattf.) woods widely used in Turkey are impregnated with Tanalith-E impregnation solution for short term (10 minutes) and medium term ( 2 hours) immersion method according to ASTM D 1413 standard. The surface roughness of the wood is determined according to the principles of TS EN 971 standards. According to tree species, the highest mean Ra roughness values; short-term impregnated European oak $(5.22 \mu \mathrm{m})$ was obtained in Oriental beech $(4.80 \mu \mathrm{m})$, Uludağ fir $(3.42 \mu \mathrm{m})$ and Scotchpine $(3.03 \mu \mathrm{m})$ respectively. Medium-term impregnated oval $(6.42 \mu \mathrm{m})$, Oriental beech $(5.020 \mu \mathrm{m})$, Uludağ fir $(4.24 \mu \mathrm{m})$ and Scotch pine $(3.74 \mu \mathrm{m})$ were obtained. As a result, short and medium time impregnation with Tanalith-E increased surface roughness values. In places where the surface roughness value is desired to be low, the use of solid Scotch pine wood may be recommended.
\end{abstract}

Keywords: Surface roughness, impregnation, Tanalith-E, wood material

Makale tarihçesi: Geliș:05.08.2019, Kabul:24.09.2019, Yayınlanma:29.12.2019, *Sorumlu yazar: khakan@ gazi.edu.tr ${ }^{1}$ Gazi Üniversitesi, Teknoloji Fakültesi, Ağaç işleri Endüstri Mühendisliği Bölümü, Beşevler - Ankara / Türkiye Atıf: Keskin H., Bülbül R., (2019), Tanalith-E ile emprenye işleminin masif ağaç malzemenin yüzey pürüzlülüğüne etkileri, Mobilya ve Ahşap Malzeme Araştırmaları Dergisi, 2 (2), 67-78. 


\section{Giriș}

Geçmişten günümüze çok çeşitli alanlarda kullanılan ağaç malzeme; çevreye zarar vermeyen, kaynağı yenilenebilir tek doğal hammaddedir. Ayrıca ekonomik ve estetik bir malzeme olması gibi birçok üstün özelliklere sahiptir. Bununla beraber anatomik yapısı, fiziksel ve mekanik özellikleri ile kimyasal bileşimi ağaç malzemenin çok farklı ürünler halinde kullanılmasına da olanak sağlamaktadır. Ağaç malzeme üstün özellikleri yanında doğal haldeki dayanıklılığı (başka bir deyişle, kullanım yerindeki değişik çevresel faktörlere karşı gösterdiği doğal dayanma süresi) yeteri kadar uzun olamamaktadır. Bunda, ahşabı tahrip ederek özelliğini bozan çeşitli biotik (bitkisel, hayvansal) ve abiotik (fiziksel, kimyasal, mekanik) zararlıların oldukça büyük bir etkisi vardır (Örs ve Keskin, 2001).

Ağaç malzemenin higroskopik bir özelliğe sahip olması nedeniyle, kullanım yerindeki havanın sıcaklık ve bağıl nemine uygun bir denge rutubetine ulaşmak için çevresindeki hava ile rutubet alışverişinde bulunmakta, bu alışveriş lif doygunluk noktası altında meydana geldiği takdirde boyutları ve hacmini değiştirmekte, yanabilmekte, biyotik ve abiyotik etkenlerle tahrip edilebilmektedir. Ahşaptan yapılan eşyalar, nemden, havadan, kimyasal maddelerden, vurma, aşınma ve sürtünme gibi fiziksel etkilerden bozulur. Bu etkiler ağaç eşyanın ömrünü kısaltır. Ayrıca, mikroorganizma adı verilen çok küçük canlılar ve bazı böcekler de yaşamlarını sürdürmek için ağacı yıkımlar (Bozkurt, 1986).

Ağaç malzemenin olumsuz özelliklerinin en aza indirilmesi ve olumlu özelliklerinin daha fazla arttırılması amacına yönelik olarak yapılan araştırma sonuçlarına göre ortaya çıkan yöntemlere "Odun Modifikasyonu Yöntemleri" denilmektedir. Odun modifikasyonu yöntemleri fiziksel ve kimyasal yönden etkili olabilmektedir. Fiziksel yönden etkili odun modifikasyonu yöntemlerinde, genellikle odunun hücre boşluklarının ve diğer kapilar boşlukların organik veya inorganik maddelerle doldurulması ve bir materyal olarak takviye edilmesi hedeflenmektedir. Kimyasal yönden etkili olan odun modifikasyonu yöntemlerinde, hücre çeperi bileşenleri ile reaksiyon veren ve böylelikle odunun kimyasal yapısını değiştiren kimyasal maddeler kullanılmakta ve böylece odunun kimyasal yapısının değiştirilerek sakıncalı özelliklerinin azaltılması yoluna gidilmektedir (Kartal ve ark., 2004).

Yüzey pürüzlülüğü, sadece ağaç malzemenin işlenme sürecine bağlı olmayıp, hücre boşlukları içerdiği için onun anatomik yapısı da yüzey pürüzlülüğünü etkilemektedir (Csanády ve ark., 2015).

Yüzey pürüzlülük değerlerine ilişkin sayısal verilerin elde edilebileceği yöntemler, homojen yapıdaki malzemeler için geliştirilen standartlarda verilmiş olup, aynı zamanda ahşap yüzeyler için de kullanılmaktadır (Özcan, 2011).

Ağaç malzeme yüzey pürüzlülüğünü ölçmede, denenmiş yöntemler içerisinde dokunmalı iğneli tarama yöntemi uygun olmaktadır (Sönmez ve Söğütlü, 2005).

Ahşap ve ahşap-esaslı ürünlerin yüzey kalitesi genellikle yüzey düzensizlikleri ile belirlenir. Düzensizlikler, yüzey pürüzlülüğü olarak değerlendirilmekte olup bunların yüksekliği, genişliği ve şekli bir ürünün yüzey kalitesini belirler. Odun işleme endüstrisinin birçok alanında yüzey kalitesi önemli bir husustur. Çünkü odun iyi planyalanmış ve/veya zımparalanmış olsa bile yüzeydeki girintilerden dolayı çok düzgün ürün yüzeyi elde edilemeyebilir (Örs ve Keskin, 2008).

Pürüzlülük, üretimde gerçekleştirilen işlemlerin sonucunda oluşan yüzeydeki hataları yansitır. Yüzey pürüzlülügünün kontrol edilmesi ve izlenmesi ürün kalitesinin üretim boyunca aynı seviyede tutulması için gereklidir. Ayrıca, yüzey pürüzlülüğü üretimin ileriki safhalarını olumsuz yönde etkileyebilmektedir (Şanıvar ve Zorlu, 1995). 
Odunun yüzey pürüzlülüğü ile ilgili yapılan araştırmalarda karşılaşılan en büyük zorluklardan biri odun türlerinin içyapılarındaki değişkenliklerdir. Bu durum, her bir odun türünün ayrı işlenmesini gerekli kılmaktadır. Bu nedenle, işlenen odunun yüzey kalitesinin hem işleme koşullarından hem de odunun özelliklerinden etkilediğini söylemek mümkündür. İşleme koşulları ile ilgili önemli faktörler kesme hızı, diş aralığı, kesme açısı, bıçak körelmesi, kesme yönü, kesme derinliği, bıçak izi, iş parçasının titreşimi ve kesme şeklidir. Odun özelliklerine ilişkin önemli faktörler ise tür, yoğunluk, rutubet miktarı, ilkbahar-yaz odunu oranı, sertlik, elastikiyet modülü ve anizotropik yapıdır (Örs ve Keskin, 2008).

Lif yönü açısı, besleme oranı, kesme hızı, kesme derinliği, rutubet miktarı, kesme yönü, bıçak/diş sayısı ve odun türü gibi faktörler planyalama ve biçme sırasında odun yüzey pürüzlülügünü doğrudan etkiler. Pürüzlülügüün azaltılması için rutubet miktarının, lif yönü açısının, besleme oranının ve kesme derinliğinin azaltılması, bıçak/diş sayısının ve kesme hızının arttırılması gerekir (Yaltırık, 1988).

Ağaç malzemelere uygulanan 120,150 veya $180^{\circ} \mathrm{C}^{\prime}$ lik sıcaklıkların uygulama süresi arttıkça malzemelerdeki yüzey pürüzlülük değerini azaltıcı yönde etki yaptığı görülmüştür. Pürüzsüz yüzeyler elde etmek için $8 \mathrm{~m} / \mathrm{dk}$ sevk hızında teğet yönde kesilmiş ve $180^{\circ} \mathrm{C}$ de $1 \mathrm{~s} 1 \mathrm{l}$ işlem görmüş Uludağ göknarı odunu tercih edilebilir (Eliçin, 1971).

Ahşap malzemeden üretilen mobilyayı son ürün halinde korumak, güzelleştirmek ve ekonomik değerini arttırmak amacıyla çeşitli üst yüzey işlemlerinin başarılı bir şekilde uygulanması da odun yüzeyinin kalitesine bağlıdır (Richter ve ark., 1995).

Ağaç malzemenin işlenmesinde, iş parçasından mekanik olarak yonga, talaş gibi parçaların uzaklaştırılması ile yüzeyde bazı istenmeyen kusurlar oluşabilmektedir. Yüzeyde oluşan bu düzensizlikler tutkallama ve üst yüzey işlemlerini olumsuz yönde etkilemektedir. Masif mobilya ve doğrama üretiminde üst yüzey işlemlerinden önce kullanılan ağaç malzeme yüzeyinin düzgünleştirilmesi gerekmektedir. $\mathrm{Bu}$ amaçla, rendeleme ve zımparalama gibi işlemler yapılmaktadır. Yeterli ve homojen bir yüzey düzgünlüğü oluşturulamadığında, yüzey işlemlerinden sonra daha da belirginleşen yüzey kusurları ürün kalitesini ve fiyatını olumsuz yönde etkilemektedir (Stumbo, 1963). Örneğin; ağaç malzemenin planyalanma aşamasında kusurlu bir yüzeyin oluşması, daha sonra yüzeyin çeşitli işlemlerle düzeltilmesini gerektirmektedir. Sonuç olarak; işgücü, malzeme, zaman vb. konularda kayıplar ortaya çıkabilmektedir. Yapılan bu işlemler sonucunda verimlilik oranında da azalma meydana gelebilmektedir (Sofuoğlu,2008).

Yüzey pürüzlülüğü, ağaç malzemeden üretilen ürünlerin yapışma direncini de etkileyebilmektedir. Düzgün yüzeylerin kaplanmasına kıyasla pürüzlü yüzeylere uygulanan kaplama işleminin yapışma kalitesini üçte bir oranında azaltabildiği bildirilmiştir (Jakub ve Martino, 2005).

Yeni nesil emprenye maddelerinden olan vacsol-aquaile emprenye işleminin, dış ortam şartlarında yaygın olarak kullanılan sapsız meşe, sarıçam ve Uludağ göknarı odunlarında yüzey pürüzlülüğünü arttırdığı fakat yapışma direncini düşürdüğü tespit edilmiştir (Keskin ve ark., 2016).

Bu çalışma, Doğu kayını (Fagus orientalis Lipsky), sarıçam (Pinus sylvestris Lipsky), sapsız meşe (Quercus petraea Liebl.) ve Uludağ göknarı (Abies nordmanniana subsp. Bornmüllerana Mattf.) odunlarının Tanalith-E ile kısa süreli (10 dakika) ve orta süreli (2 saat) emprenye edilmesinin yüzey pürüzlülüğüne etkilerinin belirlenmesi amacıyla yapılmıştır. 


\section{Materyal ve Metot}

\subsection{Materyal}

\subsubsection{Ağaç malzeme}

Ülkemiz ağaç işleri endüstrisinde yaygın olarak kullanılan Doğu kayını (Fagus orientalis Lipsky), sarıçam (Pinus sylvestris Lipsky), sapsı meşe (Quercus petraea Liebl.) ve Uludağ göknarı (Abies nordmanniana subsp. Bornmüllerana Mattf.) odunları deney malzemesi olarak seçilmiştir. Deney örnekleri, Ankara - Sitelerde bulunan kereste işletmelerinden tamamen tesadüfî yöntemle temin edilmiş ve seçiminde kerestenin kusursuz olmasına, liflerinin düzgün, ardaksız, reaksiyon odunu bulunmayan, mantar ve böcek zararlarına uğramamış olmasına özen gösterilmiştir. Odunların türlerine ait olup olmadığı makroskopik tanı metodu ile belirlenmiştir.

\subsubsection{Emprenye çözeltisi (Tanalith-E)}

Tanalith-E çözeltisi, Hemel (Hemel-Hickson Timber Products Ldt.) ürünüdür. Bu çözelti mantar, böcek ve termit gibi zararlılara karşı kullanılan, etkinliği bakır ve organik biosidlerden oluşan ve insan sağlığına zarar vermeyen yeni nesil emprenye maddesidir. Tanalith-E, açık yeşil, kahve renkli, kokusuz, yoğunluğu $1,04 \mathrm{~g} / \mathrm{cm}^{3}$ olan akıcı ve suda çözünebilir. Su bazlı, pH's1 7 ve metal kısımlarda korozyona sebep olmayan ve çözelti şeklinde piyasaya bulunmaktadır. Emprenye çözeltisi, iç ve dış mekânda; çit, bahçe mobilyaları, hayvan barınakları, silolar, çocuk oyun sahalarında kullanılan ahşabın emprenyesinde kullanılmaktadır (Hemel, 2008).

\subsection{Metot}

\subsubsection{Deney örneklerinin hazırlanması}

Deneylerde kullanılan ahşap malzemelerin kusursuz olmasına, liflerinin düzgün, budaksız, ardaksız, normal büyüme göstermiş, reaksiyon odunu bulunmayan, böcek ve mantar zararlarına uğramamış olmasına özen gösterilerek tamamen tesadüfî yöntemle temin edilmiştir. Tam ve hava kurusu yoğunluk değerleri testleri için 4 ağaç türü, 1 emprenye maddesi, 2 deney örneği ve 11 tekerrür olmak üzere toplam 88 adet deney örneği hazırlanmıştır. Deney örnekleri; planya ve kalınlık makinelerinde yüzey temizleme işleminden sonra, daire testere makinesinde 20x20x30 mm boyutlarında hazırlanmıştır. Yüzey pürüzlülüğü deneyi için 4 ağaç türü, 2 emprenye işlemi (kısa ve orta süre) ve 11 tekerrür olmak üzere toplam 88 adet deney örneği hazırlanmıştır. Deney örnekleri; planya ve kalınlık makinelerinde yüzey temizleme işleminden sonra, daire testere makinesinde 10x10x100 mm boyutlarında hazırlanmıştır. Emprenye öncesi teste tabi tutulacak yüzeylerine 80 kum zımpara ile zımparalama işlemi yapılmıştır.

Yoğunluk değerleri ve yüzey pürüzlülüğü testleri için hazırlanan deney örnekleri sıcaklığ $20 \pm 2{ }^{\circ} \mathrm{C}$ ve rutubeti $\% 65 \pm 5$ olan iklimlendirme odasında $\% 12$ denge rutubetine kadar bekletilmiştir. Daha sonra emprenye çözeltisi ile kısa süreli (10 dakika) ve orta süreli (2 saat) olarak, daldırma metodu ile emprenye edilmişlerdir. Emprenye edilen deney örnekleri, çözücünün buharlaşması için hava dolaşımı sağlanan bir odada 15 gün bekletildikten sonra sıcaklığ $120 \pm 2^{\circ} \mathrm{C}$ rutubeti $\% 65 \pm 3$ ortamda $\% 12$ rutubete ulaşıncaya kadar bekletilmiştir.

\subsubsection{Hava kurusu yoğunluk}

Hava kurusu yoğunluk tayininde TS 2472 (TSE, 1976)esaslarına uyularak 20x20x30 mm ölçülerinde hazırlanan örnekler, $20 \pm 2^{\circ} \mathrm{C}$ sıcaklık ve $\% 65 \pm 5$ bağıl nem şartlarında değişmez ağırlığa ulaşıncaya kadar bekletilmiştir. Deney örneklerinin ağırlıkları $\pm 0,01 \mathrm{~g}$ 
duyarlıklı analitik terazide tartılıp $\left(\mathrm{M}_{12}\right), \pm 0,01 \mathrm{~mm}$ duyarlıklı dijital kumpasla boyutları belirlendikten sonra hacimleri $\left(\mathrm{V}_{12}\right)$ hesaplanarak, hava kurusu yoğunluklar $\left(\delta_{12}\right)$ aşağıda verilen eşitlik (1) kullanılarak hesaplanmıştır

$$
\delta_{12}=\frac{\mathrm{M}_{12}}{\mathrm{~V}_{12}} \mathrm{~g} / \mathrm{cm}^{3}
$$

Burada; $\mathrm{M}_{12}$ : Hava kurusu halde ağırlık $(\mathrm{g}), \mathrm{V}_{12}$ : Hava kurusu halde hacim $\left(\mathrm{cm}^{3}\right)$

\subsubsection{Emprenye işlemi ve retensiyon (tutunma) miktarının belirlenmesi}

Doğu kayını, sarıçam, sapsız meşe ve Uludağ göknarı odunlarından hazırlanan deney örnekleri Tanalith-E ile ASTM D 1413 (ASTM, 2005)standardı esaslarına göre kısa süreli (10 dakika) ve orta süreli (120 dakika) olarak daldırma metodu ile emprenye edilmiştir. Daha sonra, ağırlıkları $0.001 \mathrm{~g}$ duyarlıklı analitik terazide tartılmış ve retensiyon miktarı (R),aşağıda verilen eşitlik (2) kullanılarak hesaplanmıştır.

$$
\mathrm{R}=\frac{\mathrm{G} \cdot \mathrm{C}}{\mathrm{V}} \times 10^{3} \mathrm{~kg} / \mathrm{m}^{3}, \mathrm{G}=\mathrm{T}_{2}-\mathrm{T}_{1}
$$

Burada; $\mathrm{T}_{1}$ : Emprenye sonrası deney örneği ağırlı̆̆ı $(\mathrm{g}), \mathrm{T}_{2}=$ Emprenye öncesi örnek ağırlığı (g), V: Numune hacmi $\left(\mathrm{cm}^{3}\right)$, C: Çözelti konsantrasyonu (\%).

\subsubsection{Yüzey pürüzlülüğünün belirlenmesi}

Yüzey pürüzlülüğü ölçümleri TS EN 971 (TSE, 1988) esaslarında belirtildiği üzere, ardış1k profil değişimini ölçebilen TIME TR-200 dokunmalı yüzey pürüzlülügü ölçüm test cihazı ile yapılmıştır. Ölçüm cihazına ait teknik özellikler Çizelge 1'de verilmiştir.

Çizelge 1. Yüzey pürüzlülüğ̈̈ test cihazına ilişkin teknik özellikler (EN 971)

\begin{tabular}{|l|l|}
\hline Tipi & TR -200 \\
\hline Ölçme Parametreleri & Ra, Rz, Ry, Rq, Rt, Rp, Rmaks, Rm, R3z \\
\hline Ölçme Hassasiyeti & $0,01-0,04 \mu \mathrm{m}$ \\
\hline Ölçme Standardı & ISO 4287, DIN 4768, JIS B601 \\
\hline Enerji Kaynağı & Lithiumion şarj edilebilir batarya \\
\hline Ölçme Boyu & Otomatik, 0,25 mm, 0,8 mm, 2,5 mm \\
\hline Ölçüm Sayısı (Cut-Off) & $1-5$ Adet (ayarlanabilir) \\
\hline Uygun Çalışma Sıcaklık ve Nemi & $0-40^{\circ} \mathrm{C}$ ve $<\% 90$ Bağıl nem \\
\hline Boyutlar ve Ağırlık & $140 * 52 * 48$ mm ve 500 g \\
\hline Sonuç Alma & LCD Ekran, yazıcı veya PC'ye aktarma \\
\hline
\end{tabular}

Yüzey pürüzlülüğü ölçümleri liflere dik yönde yapılmıştır. Cihaz, 2,5 mm ölçme adımı ve 3 ölçme sayısına (cut-off) ayarlandıktan sonra ölçme kolu, aralığı $20 \mathrm{~mm}$ olan iki çizgi arasına yerleştirilmiştir. Örneğin ve cihazın yer düzlemine paralellik durumu kontrol edildikten sonra ölçüm başlatılmıştır. Sonuç, cihazın LCD ekranından okunarak Ra cinsinden kaydedilmiştir (Sönmez ve Söğütlü, 2005). Yüzey pürüzlülüğü ölçme cihazı Şekil 1'de görülmektedir. 


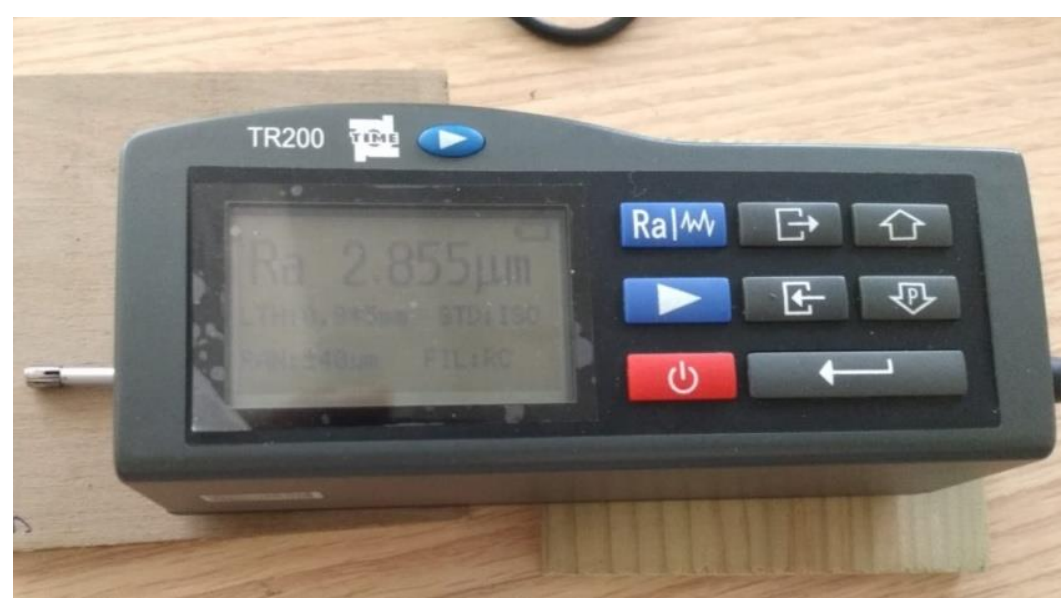

Şekil 1. Yüzey pürüzlülüğü ölçme cihazı

Ölçüm cihaz, yüzey pürüzlülüğünü, tarama iğnesinin $5 \mu \mathrm{m}$ çaplı elmas ucunu, örnek yüzeyinde aşağı-yukarı hareket ettirerek yüzeyde bulunan girinti ve çıkıntıların profilini çıkartarak ölçmektedir. Profil girintileri (vadi) ile çıkıntıları (tepe) arasında bulunan ortalama sapma (Ra), düzensizliğin on noktadaki yüksekliğinin ortalaması $(\mathrm{Rz})$ ve profilin en fazla yüksekliği (Ry) parametreleridir. Bu çalışmada, yüzey pürüzlülüğü Ra parametresi esasına göre değerlendirilmiştir. Ra yüzey pürüzlülük değeri; TS EN 971'e göre yüzey pürüzlülük profilinde profil sapmalarının (tepe ve çukur) aritmetik ortalamasıdır. Ra pürüzlülük değeri aşağıdaki formülle (3) hesaplanabilmektedir (TSE, 1988).

$$
R a=1 / I \int_{0}^{T} Z(x) \mid d x
$$

Burada; $\mathrm{Z}(\mathrm{x})$; örnekleme boyu içinde, mutlak değerlerin aritmetik ortalaması, $\mathrm{dx}$; değerlendirilen profilin, $X_{\mathrm{I}}$; konumundaki eğimi, I ; örnekleme boyudur.

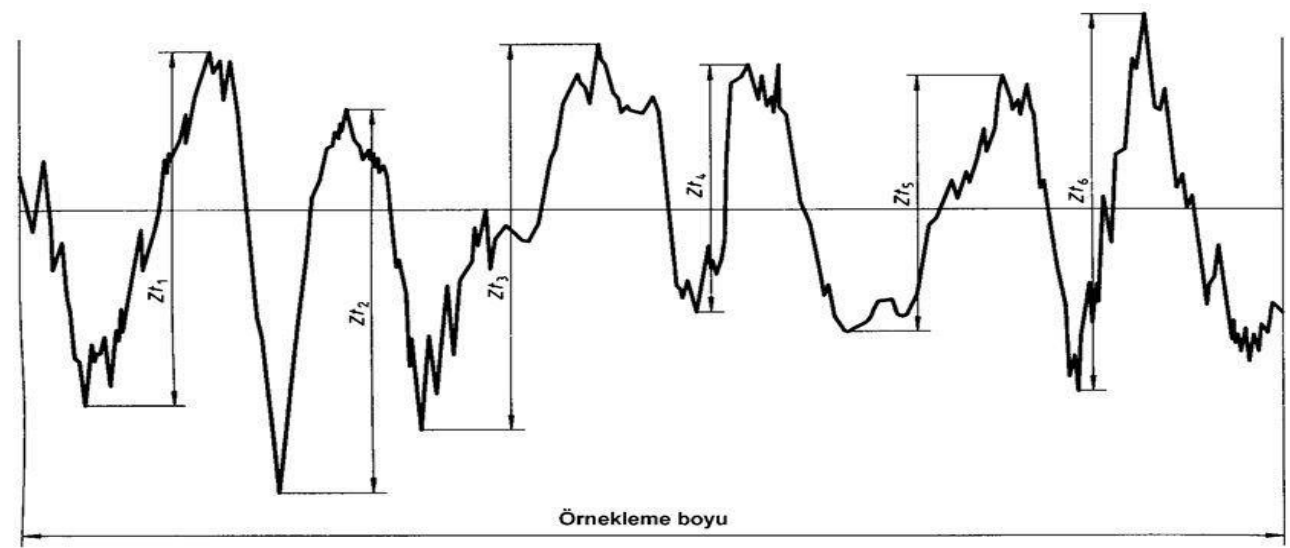

Şekil 2. Profil elemanlarının yüksekliği

\subsection{Veri Analizi}

Tanalit-E çözeltisi ile emprenye edilmiş Doğu kayını, sarıçam, sapsız meşe ve Uludağ göknarı odunlarının yoğunluk (tam kuru ve hava kurusu yoğunluk), yüzey pürüzlülük değerleri arasındaki farkın belirlenmesinde varyans analizi (F testi) kullanılmıştır. Deneme grupları arasındaki farklılığın önemli çıkması halinde $(\alpha=0,05)$ güven düzeyinde Duncan testi ile karşılaştırılmıştır. Deneylerde elde edilen dataların istatistiksel analizinde SPSS 22 istatistik programı kullanılmıştır 


\section{Bulgular ve Tartışma}

\subsection{Hava kurusu yoğunluk}

Deneylerde kullanılan örneklerin hava kurusu yoğunluk ortalamaları Çizelge 2'de varyans analizi (ANOVA) sonuçları ise Çizelge 3'de verilmiştir.

Çizelge 2. Hava kurusu yoğunluk ortalamaları $\left(\mathrm{g} / \mathrm{cm}^{3}\right)$

\begin{tabular}{|l|l|l|ll|}
\hline \multirow{2}{*}{$\begin{array}{l}\text { İstatistik } \\
\text { Değerler }\end{array}$} & \multicolumn{4}{|l}{ Ăgaç malzeme türü } \\
\cline { 2 - 5 } & Kayın & Meşe & Sarıçam & Göknar \\
\hline $\mathrm{X}$ & 0.688 & 0.731 & 0.595 & 0.534 \\
\hline ss & 0.02959423 & 0.03020946 & 0.04962487 & 0.02264056 \\
\hline $\mathrm{v}$ & 0.0009634 & 0.00100387 & 0.00270889 & 0.00056385 \\
\hline $\min$ & 0.642 & 0.692 & 0.543 & 0.509 \\
\hline $\max$ & 0.744 & 0.788 & 0.687 & 0.591 \\
\hline $\mathrm{N}$ & 11 & 11 & 11 & 11 \\
\hline
\end{tabular}

Çizelge 3. Hava kurusu yoğunluk varyans analizi (ANOVA)

\begin{tabular}{|l|l|l|l|l|c|}
\hline $\begin{array}{l}\text { Varyans } \\
\text { Kaynağ1 }\end{array}$ & $\begin{array}{l}\text { Kareler } \\
\text { Toplam1 }\end{array}$ & $\begin{array}{l}\text { Serbestlik } \\
\text { Derecesi }\end{array}$ & $\begin{array}{l}\text { Kareler } \\
\text { Ortalamas1 }\end{array}$ & F değeri & $\begin{array}{l}* \text { Önem } \\
\text { Düzeyi }\end{array}$ \\
\hline Gruplar aras1 & 0.261 & 3 & 0.087 & 66.508 & 0.000 \\
\hline Grup içi & 0.052 & 40 & 0.001 & & \\
\hline Toplam & 0.314 & 43 & & & \\
\hline
\end{tabular}

$* P<0,05$

Deney örneklerinin hava kurusu yoğunluk ortalamaları için yapılan F testine göre; hava kurusu yoğunluk değerleri ahşap türlerine göre istatistiksel anlamda önemli farklılık göstermiştir $(\mathrm{P}<0.05)$. Duncan testi sonuçlarına göre; en yüksek hava kurusu yoğunluk değeri sapsız meşe odununda $\left(0.731 \mathrm{~g} / \mathrm{cm}^{3}\right)$ elde edilmiş bunu sırasıyla; Doğu kayını $\left(0.688 \mathrm{~g} / \mathrm{cm}^{3}\right)$, Sarıçam $\left(0.595 \mathrm{~g} / \mathrm{cm}^{3}\right)$ ve Uludağ göknarı $\left(0.534 \mathrm{~g} / \mathrm{cm}^{3}\right)$ izlemiştir. Deneylerden elde edilen değerler, literatür değerleri ile paralellik göstermektedir (Temel, 2016).

\subsection{Retensiyon (tutunma) miktarı}

\subsubsection{Kısa süreli emprenye edilmiş örneklerin retensiyon miktarı}

Kısa süreli emprenye edilmiş deney örneklerin retensiyon miktarına ait istatistik değerler Çizelge 4'de, örneklerin retensiyon miktarı ortalamalarına ait varyans analizi (ANOVA) F testi sonuçları Çizelge 5'de verilmiştir.

Çizelge 4. Kısa süreli retensiyon miktarları $\left(\mathrm{kg} / \mathrm{m}^{3}\right)$

\begin{tabular}{|l|l|l|l|l|}
\hline \multirow{2}{*}{$\begin{array}{l}\text { İstatistik } \\
\text { değerler }\end{array}$} & \multicolumn{4}{|l|}{ Kisa süreli emprenyeli ağaç malzeme türü } \\
\cline { 2 - 5 } & Kayın & Meşe & Sarı̧̧am & Göknar \\
\hline $\mathrm{X}$ & 84.106 & 60.816 & 71.742 & 78.341 \\
\hline $\mathrm{ss}$ & 3.18070916 & 6.35690233 & 5.73444922 & 4.214145273 \\
\hline $\mathrm{v}\left(\mathrm{s}^{2}\right)$ & 11.1286018 & 44.451228 & 36.1722987 & 19.53492242 \\
\hline $\min$ & 79.496 & 54.161 & 59.094 & 73.265 \\
\hline $\max$ & 88.802 & 77.302 & 80.294 & 89.551 \\
\hline $\mathrm{N}$ & 11 & 11 & 11 & 11 \\
\hline
\end{tabular}


Çizelge 5. Kısa süreli emprenyeli örneklerin retensiyon ortalamaları varyans analizi

\begin{tabular}{|l|l|l|l|l|c|}
\hline $\begin{array}{l}\text { Varyans } \\
\text { Kaynağ1 }\end{array}$ & $\begin{array}{l}\text { Kareler } \\
\text { Toplam1 }\end{array}$ & $\begin{array}{l}\text { Serbestlik } \\
\text { Derecesi }\end{array}$ & $\begin{array}{l}\text { Kareler } \\
\text { Ortalamas1 }\end{array}$ & F değeri & $\begin{array}{c}* \text { Önem } \\
\text { Düzeyi }\end{array}$ \\
\hline Gruplar aras1 & 3295.929 & 3 & 1098.643 & 39.489 & 0.000 \\
\hline Grup içi & 1112.871 & 40 & 27.822 & & \\
\hline Toplam & 4408.800 & 43 & & & \\
\hline$* P<0,05$
\end{tabular}

Duncan testi sonuçlarına göre; en yüksek retensiyon değeri Doğu kayını odununda $\left(84.106 \mathrm{~g} / \mathrm{cm}^{3}\right)$ elde edilmiş bunu sırasıyla; Uludağ göknarı $\left(78.341 \mathrm{~kg} / \mathrm{m}^{3}\right)$, sarıçam $(71.742$ $\left.\mathrm{kg} / \mathrm{m}^{3}\right)$ ve sapsız meşe $\left(60.816 \mathrm{~kg} / \mathrm{m}^{3}\right)$ izlemiştir.

\subsubsection{Orta süreli emprenye edilmiş örneklerin retensiyon miktarı}

Orta süreli emprenye edilmiş örneklerin retensiyon miktarı ortalamalarına ait istatistik değerler Çizelge 6'da, varyans analizi sonuçları ise Çizelge 7'de verilmiştir.

Çizelge 6. Orta süreli retensiyon miktarları $\left(\mathrm{kg} / \mathrm{m}^{3}\right)$

\begin{tabular}{|l|l|l|l|l|}
\hline \multirow{2}{*}{$\begin{array}{l}\text { İstatistik } \\
\text { değerler }\end{array}$} & \multicolumn{4}{|l|}{ Orta süreli emprenyeli ağaç malzeme türü } \\
\cline { 2 - 5 } & Kayın & Meşe & Sarıçam & Göknar \\
\hline $\mathrm{X}$ & 94.218 & 70.503 & 78.063 & 86.223 \\
\hline $\mathrm{ss}$ & 3.44872383 & 4.03341184 & 6.45250668 & 5.636249043 \\
\hline $\mathrm{v}\left(s^{2}\right)$ & 13.0830657 & 17.8952522 & 45.7983267 & 34.9440336 \\
\hline $\min$ & 87.312 & 66.534 & 67.234 & 78.329 \\
\hline $\max$ & 99.852 & 78.232 & 90.214 & 100.012 \\
\hline
\end{tabular}

Çizelge 7. Orta süreli emprenyeli örneklerin retensiyon miktarları varyans analizi

\begin{tabular}{|l|l|r|r|r|c|}
\hline $\begin{array}{l}\text { Varyans } \\
\text { Kaynağı }\end{array}$ & $\begin{array}{l}\text { Kareler } \\
\text { Toplam1 }\end{array}$ & $\begin{array}{l}\text { Serbestlik } \\
\text { Derecesi }\end{array}$ & $\begin{array}{l}\text { Kareler } \\
\text { Ortalamas } 1\end{array}$ & F değeri & $\begin{array}{c}* \text { Önem } \\
\text { Düzeyi }\end{array}$ \\
\hline Gruplar aras1 & 3460.010 & 3 & 1153.337 & 41.294 & 0.000 \\
\hline Grup içi & 1117.207 & 40 & 27.930 & & \\
\hline Toplam & 4577.217 & 43 & & & \\
\hline & $*<<0,05$
\end{tabular}

Orta süreli emprenye edilmiş ahşap malzemelerin retensiyon değerleri için yapılan $F$ testine göre; retensiyon değerleri ahşap türlerine göre istatistiksel anlamda önemli farklılık göstermiştir $(\mathrm{P}<0.05)$. Duncan testi sonuçlarına göre; en yüksek retensiyon değeri Doğu kayını odununda $\left(94.218 \mathrm{~kg} / \mathrm{m}^{3}\right)$ elde edilmiş bunu sırasıyla; Uludağ göknarı $\left(86.223 \mathrm{~kg} / \mathrm{m}^{3}\right)$, sarıçam $\left(78.063 \mathrm{~kg} / \mathrm{m}^{3}\right)$ ve sapsız meşe $\left(70.503 \mathrm{~kg} / \mathrm{m}^{3}\right)$ izlemiştir.

\subsection{Yüzey pürüzlülüğü}

Tanalith-E ile kısa ve orta süreli emprenye edilen masif ağaç deney örnekleri ve emprenyesiz kontrol örneklerinin yüzey pürüzlülüğüne $(\mathrm{Ra})$ ait istatistiksel değerler Çizelge 8'de verilmiştir. 
Çizelge 8. Yüzey pürüzlülüğü Ra değerleri $(\mu \mathrm{m})$

\begin{tabular}{|c|c|c|c|c|}
\hline \multirow{2}{*}{$\begin{array}{l}\text { Istatistik } \\
\text { değerler }\end{array}$} & \multicolumn{4}{|c|}{$\mathrm{Ra}$ (K1sa süre emprenyeli) } \\
\hline & Kayıı & Meşe & Sarıçam & Göknar \\
\hline $\mathrm{X}$ & 4.802 & 5.228 & 3.038 & 3.423 \\
\hline Ss & 0.423143 & 0.692892 & 0.55153 & 0.345618 \\
\hline $\mathrm{v}\left(\mathrm{s}^{2}\right)$ & 0.196955 & 0.528109 & 0.33461 & 0.131397 \\
\hline $\min$ & 3.819 & 4.012 & 2.144 & 2.751 \\
\hline $\max$ & 5.392 & 6.015 & 3.632 & 4.045 \\
\hline \multirow{2}{*}{$\begin{array}{l}\text { İstatistik } \\
\text { değerler }\end{array}$} & \multicolumn{4}{|c|}{ Ra (Orta sure emprenyeli) } \\
\hline & Kayin & Meşe & Sarıçam & Göknar \\
\hline $\mathrm{X}$ & 5.028 & 6.421 & 3.741 & 4.246 \\
\hline Ss & 0.579763 & 0.777684 & 0.31031 & 0.421995 \\
\hline $\mathrm{V}\left(\mathrm{s}^{2}\right)$ & 0.369737 & 0.665272 & 0.10592 & 0.195888 \\
\hline $\min$ & 4.099 & 5.377 & 3.395 & 3.615 \\
\hline $\max$ & 5.758 & 7.579 & 4.416 & 4.89 \\
\hline \multirow{2}{*}{$\begin{array}{l}\text { İstatistik } \\
\text { değerler }\end{array}$} & \multicolumn{4}{|c|}{ Ra (Konrol örneği - emprenyesiz) } \\
\hline & Kayıı & Meşe & Sarıçam & Göknar \\
\hline $\mathrm{X}$ & 4.5560909 & 5.0332727 & 2.93045 & 3.3548182 \\
\hline SS & 0.5174974 & 0.3975868 & 0.52999 & 0.3679809 \\
\hline $\mathrm{V}\left(\mathrm{s}^{2}\right)$ & 0.2945839 & 0.1738828 & 0.30898 & 0.148951 \\
\hline $\min$ & 3.356 & 4.239 & 2.014 & 2.333 \\
\hline $\max$ & 5.187 & 5.484 & 3.972 & 3.885 \\
\hline
\end{tabular}

Tanalith-E ile kısa ve orta süreli emprenye edilen ağaç malzemelerin ve kontrol örneklerinin Ra yüzey pürüzlülüğü değerleri için yapılan F testine göre (Çizelge 9); yüzey pürüzlülüğü değerleri ağaç türlerine göre istatistiksel anlamda önemli farklılıklar göstermiştir $(\mathrm{P}<0.05)$.

Çizelge 9. Yüzey pürüzlülüğü $(\mathrm{Ra})$ varyans analizi F testi

\begin{tabular}{|l|l|l|l|l|l|}
\hline $\begin{array}{l}\text { Varyans } \\
\text { Kaynağ1 }\end{array}$ & $\begin{array}{l}\text { Kareler } \\
\text { Toplamı }\end{array}$ & $\begin{array}{l}\text { Serbestlik } \\
\text { Derecesi }\end{array}$ & $\begin{array}{l}\text { Kareler } \\
\text { Ortalamas1 }\end{array}$ & F değeri & $\begin{array}{l}* \text { Önem } \\
\text { Düzeyi }\end{array}$ \\
\hline Gruplar aras1 & 134.097 & 11 & 12.191 & 42.350 & 0.000 \\
\hline Grup içi & 34.543 & 120 & 0.288 & & \\
\hline TOPLAM & 168.640 & 131 & & & \\
\hline *P<0,05
\end{tabular}

Yüzey pürüzlülüğü değerleri için yapılan Duncan testi sonuçlarına göre; en yüksek yüzey pürüzlülügü değeri orta süre emprenyeli meşe odununda $(6.421 \mu \mathrm{m})$ elde edilmiş, en düşük değerler ise emprenyesiz sarıçam kontrol örneğinde elde edilmiştir. Kontrol sarıçam ve göknar örnekleri ile kısa süre emprenyeli sarıçam deney örnekleri arasındaki matematiksel fark, istatistiksel anlamda önemsiz bulunmuştur (Çizelge 10).

Varyans analizi sonuçlarına göre emprenyeli ağaç malzemelerin yüzey pürüzlülüğü Ra değerlerinin grafiksel ifadesi Şekil 3'de verilmiştir. 
Çizelge 10. Yüzey pürüzlülüğü $(\mathrm{Ra})$ Duncan testi

\begin{tabular}{|l|l|l|l|l|l|l|l|l|}
\hline \multirow{2}{*}{ GRUP } & \multirow{2}{*}{$\mathrm{N}$} & \multicolumn{6}{|l|}{ Alt gruplar için $\alpha=0,05$} & \multicolumn{7}{l|}{} \\
\hline & & 1 & 2 & 3 & 4 & 5 & 6 & 7 \\
\hline Sc & 11 & 2,930 & & & & & & \\
\hline Sk & 11 & 3,038 & 3,038 & & & & & \\
\hline Gc & 11 & 3,354 & 3,354 & 3,354 & & & & \\
\hline Gk & 11 & & 3,423 & 3,423 & & & & \\
\hline So & 11 & & & 3,741 & & & & \\
\hline Go & 11 & & & & 4,246 & & & \\
\hline Kc & 11 & & & & 4,556 & 4,556 & & \\
\hline Kk & 11 & & & & & 4,802 & 4,802 & \\
\hline Ko & 11 & & & & & 5,028 & 5,028 & \\
\hline Mc & 11 & & & & & 5,033 & 5,033 & \\
\hline Mk & 11 & & & & & & 5,228 & \\
\hline Mo & 11 & & & & & & & 6,421 \\
\hline ÖnemDüzeyi & 0,82 & 0,115 & 0,114 & 0,179 & 0,058 & 0,092 & 1,000 \\
\hline
\end{tabular}

G: Göknar, S: Sarıçam, M: Meşe, K: Kayın, k: kisa süreli emprenyeli, o: orta süreli emprenyeli, c: kontrol

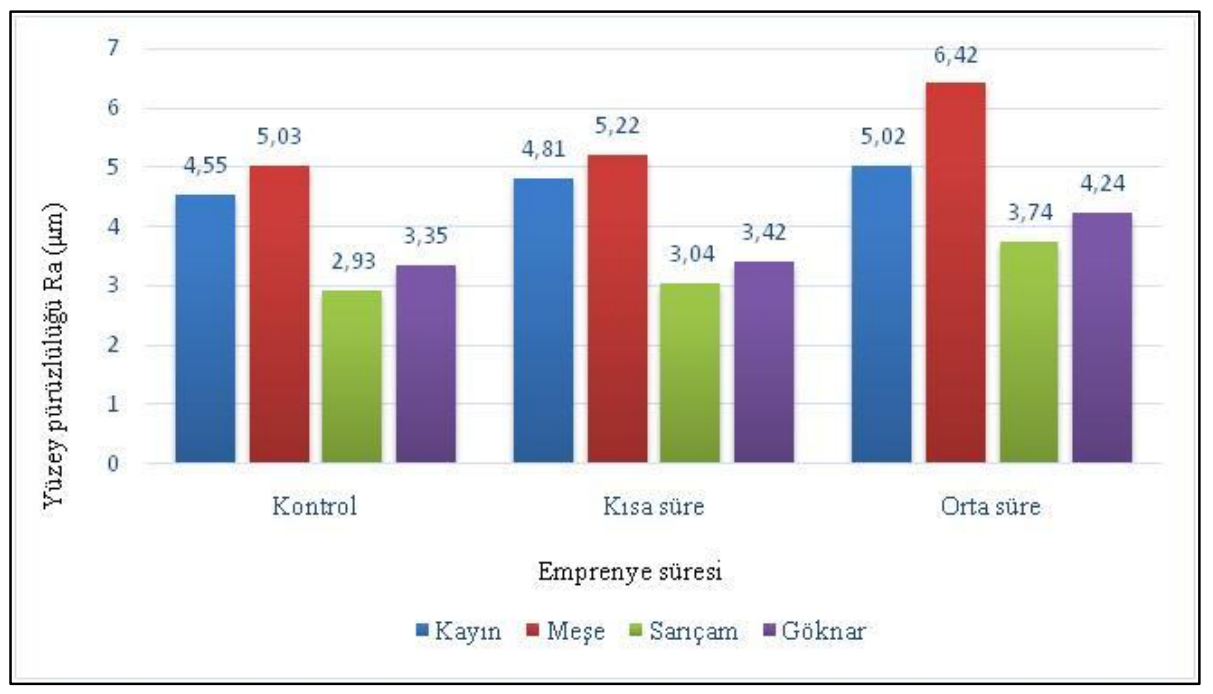

Şekil 3. Yüzey pürüzlülüğü değerleri

$\mathrm{Bu}$ sonuçlara göre; ağaç türü ve emprenye işleminin yüzey pürüzlüğünü etkilediği, Tanalith-E ile emprenye edilen ağaç malzemelerin yüzey pürüzlülüğünün, emprenye süresi arttıkça yüzey pürüzlülügünü de arttırmaktadır. Bulunan bu değerler, literatür değerleri ile paralellik göstermektedir (Sönmez ve Sögütlü, 2005).

\section{Sonuçlar ve Öneriler}

Araştırmada, Tanalit-E çözeltisi ile emprenye edilen Doğu kayını, Sapsız meşe, Sarıçam ve Uludağ göknarı odunlarının yüzey pürüzlülük özellikleri incelenmiş ve deneylerden elde edilen sonuç ve öneriler aşağıda verilmiştir. 
- Ağaç türlerine göre en yüksek ortalama hava kurusu yoğunluk değeri, sapsız meşe odununda elde edilmiş bunu sırasıyla; Doğu kayını, sarıçam ve Uludağ göknarı izlemiştir.

- Kısa süreli emprenye işleminde ağaç türlerine göre en yüksek ortalama retensiyon miktarları Doğu kayını odununda olmak üzere sırasıyla; Uludağ göknarı, sarıçam, sapsız meşe odunlarında elde edilmiştir.

- Orta süreli emprenye işleminde ağaç türlerine göre; en yüksek ortalama retensiyon miktarları Doğu kayını olmak üzere sırasıyla; Uludağ göknarı, sarıçam ve sapsız meşe odunlarında elde edilmiştir.

- Kısa ve orta süreli emprenyeli sapsız meşe odununda retensiyon oranının düşük çıkması tül oluşumundan kaynaklanabilir.

- Kısa ve orta süreli emprenye edilen ağaç malzemelerin en yüksek Ra yüzey pürüzlülügü değerleri; sapsız meşe odununda elde edilmiş, bunu sırası ile Doğu kayını, Uludağ göknarı ve sarıçam izlemiştir.

- Tanalith-E ile emprenye edilen ağaç malzemelerin Ra yüzey pürüzlülüğü değeri, emprenye süresi arttıkça doğru orantılı olarak yüzey pürüzlülüğünü de arttırmaktadır.

- Tanalith-E emprenye edilmiş ağaç malzemelerde; yüzey pürüzlülüğü az olması istenilen yerlerde ise sarıçam kullanımı önerilebilir.

\section{Teşekkür}

$\mathrm{Bu}$ çalışma, Gazi Üniversitesi, Fen Bilimleri Enstitüsü, Ağaç işleri Endüstri Mühendisliği Anabilim Dalında, Ramazan Bülbül tarafından hazırlanan Yüksek Lisans tezinden üretilmiştir.

\section{Kaynaklar}

ASTM D 1413-99, (2005), Standard method of testing wood preservatives by laboratory soil block cultures, Annual Book of ASTM Standards, West Conshohocken, PA.

Bozkurt, Y., (1986), Ağaç teknolojisi, İstanbul Üniversitesi Orman Fakültesi Yayınlarl, No: 3403, İstanbul

Csanády, E., Magoss, E., Tolvaj, L., (2015), Quality of machined wood surfaces, Springer International Publishing, Basel.

Eliçin, G., (1971), Türkiye sarıçam (Pinus silvestris Lipsky) orijinlerinde morfo-genetik araştırmalar, İstanbul Üniversitesi Orman Fakültesi Dergisi, Seri B, Cilt XVII, sayı 1., İstanbul.

Hemel Emprenye Sanayi A.Ş., (2008), Tanalith-E brochure, data sheets, Timber Treatment Products, No: 22.

Jakub, S., Martino, N., (2005), Wood surface roughness-what is it?, Rosenheim Workshop, BOKU University of Natural Sources and Applied Life Sciences, 29-30 September, Vienna, Austria.

Kartal, S.N., Dorau, B, Lebow, S.T., Green, F. (2004a), Effects of inorganicions on leachability of wood preserving n'n-hydroxynaphtalimide, Forest Product Journal, 54(1), 80-84, USA.

Keskin, H., Kesik, H.İ., Temel, F., Öztürk, Y., (2016), Vacsol aqua ile emprenye edilmiş bazı ağaç malzemelerin yüzey pürüzlülüğü ve yapışma direnç özellikleri, Kastamonu Üniversitesi Orman Fakültesi Dergisi, 16(1), 181-189. 
Örs, Y., Keskin, H., (2001), Ağaç malzeme bilgisi, Ders Kitabı, Atlas Yayınları, İstanbul.

Örs, Y., Keskin, H., (2008), Ağaç malzeme teknolojisi, Gazi Yayınları, No:2000/352, Ankara.

Özcan S., (2011), Ağaç malzeme türü, sıcaklık farkı ve yüzey pürüzlülüğünün yapışma direncine etkileri, Karabük Üniversitesi Fen Bilimleri Enstitüsü Yüksek Lisans Tezi, Karabük.

Richter, K., Feist. W.C., Knaebe, M.T., (1995), The effect of surface roughness on the performance of finishes, Forest Products Journal, 45(7), 91-97.

Sofuoğlu, S.D., (2008), Bazı yerli ağaç türü odunlarının işlenme özelliklerinin yüzey kalitesi üzerine etkileri, Ístanbul Üniversitesi Fen Bilimleri Enstitüsü Yüksek Lisans Tezi, İstanbul.

Sönmez, A., Söğütlü, C., (2005), Rendeleme işleminin ağaç malzeme yüzey pürüzlülüğüne etkisi, Zonguldak Karaelmas Üniversitesi Karabük Teknik Eğitim Fakültesi Teknoloji Dergisi, 8(3), 287-293.

Stumbo, D.A., (1963), Surface texture measurement methods. Forest Products Journal, 13, 299-304.

Şanıvar, N., Zorlu, İ., (1995), Ağaç işleri gereç bilgisi, İstanbul Üniversitesi Orman Fakültesi Yayınlarl, 306-314, İstanbul.

Temel, F., (2016), Vacsol-aqua ile emprenye işleminin ağaç malzemenin yüzey pürüzlülüğü ve yapışma direncine etkileri, G.Ü. Fen Bilimleri Enstitüsü Yüksek Lisans Tezi, Ankara

TS 2472, (1976), Odun fiziksel ve mekaniksel deneyler için birim hacim ağırlığı tayini, Türk Standartları Enstitüsü, Ankara.

TS EN 971, (1988), Yüzey pürüzlülügü - parametreler ve pürüzlülük tespiti kuralları, Türk Standartları Enstitüsü, Ankara.

Yaltırık, F., (1988), Dendroloji I, İstanbul Üniversitesi Orman Fakültesi, Yayın No: 2410, İstanbul. 